Check for updates

Cite this: Phys. Chem. Chem. Phys., 2018, 20, 3761

Received 30th November 2017 Accepted 12th January 2018

DOI: $10.1039 / c 7 c p 08056 e$

rsc.li/pccp

\section{Absolute and relative-rate measurement of the rate coefficient for reaction of perfluoro ethyl vinyl ether $\left(\mathrm{C}_{2} \mathrm{~F}_{5} \mathrm{OCF}=\mathrm{CF}_{2}\right)$ with $\mathrm{OH}$}

\author{
G. Srinivasulu, A. J. C. Bunkan, D. Amedro and J. N. Crowley (D) *
}

The rate coefficient $\left(k_{1}\right)$ for the reaction of $\mathrm{OH}$ radicals with perfluoro ethyl vinyl ether (PEVE, $\mathrm{C}_{2} \mathrm{~F}_{5} \mathrm{OCF}=\mathrm{CF}_{2}$ ) has been measured as a function of temperature $(T=207-300 \mathrm{~K})$ using the technique of pulsed laser photolysis with detection of $\mathrm{OH}$ by laser-induced fluorescence (PLP-LIF) at pressures of 50 or 100 Torr $\mathrm{N}_{2}$ bath gas. In addition, the rate coefficient was measured at $298 \mathrm{~K}$ and in one atmosphere of air by the relative-rate technique with loss of PEVE and reference reactant monitored in situ by IR absorption spectroscopy. The rate coefficient has a negative temperature dependence which can be parameterized as: $k_{1}(T)=6.0 \times 10^{-13} \exp [(480 \pm 38 / T)] \mathrm{cm}^{3}$ molecule ${ }^{-1} \mathrm{~s}^{-1}$ and a room temperature value of $k_{1}(298 \mathrm{~K})=(3.0 \pm 0.3) \times 10^{-12} \mathrm{~cm}^{3}$ molecule ${ }^{-1} \mathrm{~s}^{-1}$. Highly accurate rate coefficients from the PLP-LIF experiments were achieved by optical on-line measurements of PEVE and by performing the measurements at two different apparatuses. The large rate coefficient and the temperature dependence indicate that the reaction proceeds via $\mathrm{OH}$ addition to the $\mathrm{C}=\mathrm{C}$ double bond, the high pressure limit already being reached at 50 Torr $\mathrm{N}_{2}$. Based on the rate coefficient and average $\mathrm{OH}$ levels, the atmospheric lifetime of PEVE was estimated to be a few days.

\section{Introduction}

Desirable properties such as thermal and chemical resistance have led to the use of fluoropolymers in many industrial processes including the production of plastics, elastomers or membranes ${ }^{1,2}$ and to their production in large quantities. The most important commercial fluoropolymers are homopolymers based on only three main monomers; tetrafluoroethylene (TFE), vinyl fluoride and vinylidene fluoride. ${ }^{3}$ In addition, smaller amounts of co-polymers with tailored properties are made with co-monomers like hexafluoropropylene and perfluoro vinyl ethers.

Since perfluorinated compounds generally have strong absorption features in the atmospheric infrared window and often have long atmospheric lifetimes, many of them are very potent greenhouse gases. ${ }^{4-6}$ To evaluate their impact on climate change, accurate assessment of their atmospheric sinks is essential. From a physical chemical perspective, we note that the reaction kinetics of perfluoro substituted organic trace gases can differ greatly from the non-fluorinated analogues. Study of the $\mathrm{OH}$ reaction with a fluorinated ethyl vinyl ether (electrophilic addition of $\mathrm{OH}$ to the $\mathrm{C}=\mathrm{C}$ double bond) allows us to analyse the electronic effects caused by the presence of a fluorinated alkyl

Division of Atmospheric Chemistry, Max-Planck-Institut für Chemie, 55128 Mainz, Germany.E-mail: john.crowley@mpic.de group separated from the electron rich double bond by the ether linkage.

To the best of our knowledge, there are no published studies on the atmospheric fate of perfluoro ethyl vinyl ether $\left(\mathrm{C}_{2} \mathrm{~F}_{5} \mathrm{OCF}=\mathrm{CF}_{2}\right.$, henceforth PEVE $)$ though a few experimental studies on related reactions of perfluoro methyl vinyl ether ${ }^{7-9}$ and perfluoro propyl vinyl ether ${ }^{10}$ exist. In this work we have studied the kinetics of the reaction of PEVE with $\mathrm{OH}$ radicals (R1) using both the technique of pulsed laser photolysis with detection of $\mathrm{OH}$ radicals by laser-induced fluorescence as well as relative-rate measurements using FTIR detection of reactants to derive the rate coefficient, $k_{1}$.

$$
\mathrm{OH}+\mathrm{PEVE} \rightarrow \text { products }
$$

\section{Experimental methods}

Both absolute and relative-rate methods were used to determine the rate coefficient, $k_{1}$, for the title reaction.

\subsection{Pulsed laser photolysis, laser-induced fluorescence} (PLP-LIF)

Absolute rate coefficients were determined using the pulsed laser photolysis, laser-induced fluorescence technique with two different experimental set-ups (PLP-LIF1 and PLP-LIF2). 


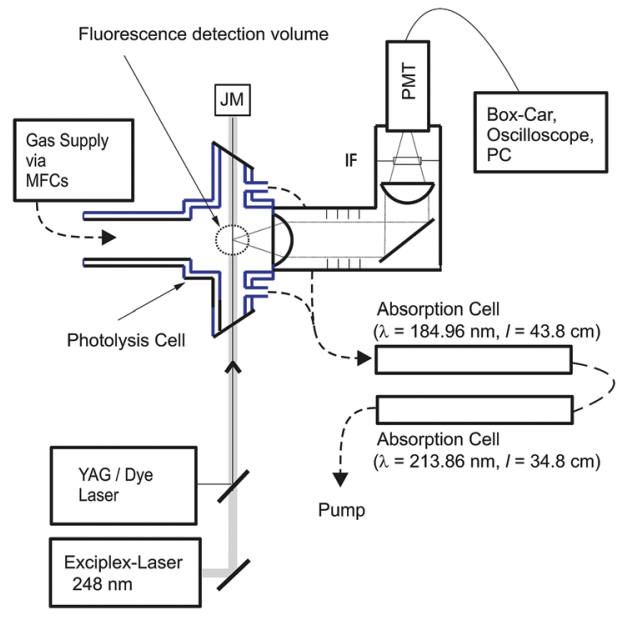

Fig. 1 Experimental setup (PLP-LIF1) for the absolute measurements of $k_{1}(T) . M F C=$ mass flow controller, $\mathrm{JM}=$ joule meter, $\mathrm{PMT}=$ photomultiplier tube, IF = interference filter

The one used for most of the measurements (PLP-LIF1), is shown in Fig. 1. This apparatus has been described in detail elsewhere $^{11}$ and only a brief description will be given here. The quartz reaction cell has a volume of $\approx 500 \mathrm{~cm}^{3}$ and can be thermostatted to the desired temperature by circulating ethanol through its jacket. The measurements were performed at temperatures between 207 and $300 \mathrm{~K}$ at pressures of 50 and 100 Torr $\mathrm{N}_{2}$ and $10 \mathrm{~Hz}$ laser repetition rate. The gas flow, regulated using calibrated mass flow controllers (MKS), was chosen to ensure that a fresh gas mixture was available for each laser pulse.

When using PLP-LIF1, OH radicals were generated by pulsed photolysis of $\mathrm{H}_{2} \mathrm{O}_{2}$ or $\mathrm{HNO}_{3}$ at $248 \mathrm{~nm}$ using an exciplex laser (LambdaPhysik 300i).

$$
\begin{gathered}
\mathrm{H}_{2} \mathrm{O}_{2}+h \nu \rightarrow 2 \mathrm{OH} \\
\mathrm{HNO}_{3}+h \nu \rightarrow \mathrm{OH}+\mathrm{NO}_{2}
\end{gathered}
$$

The concentrations of $\mathrm{H}_{2} \mathrm{O}_{2}\left(1-2 \times 10^{14}\right.$ molecule $\left.\mathrm{cm}^{-3}\right)$ and $\mathrm{HNO}_{3}\left(4-6 \times 10^{14}\right.$ molecule $\left.\mathrm{cm}^{-3}\right)$ were measured by on-line optical absorption at $213.86 \mathrm{~nm}$ and $184.95 \mathrm{~nm}$, respectively using low pressure $\mathrm{Zn}$ and $\mathrm{Hg}$ lamps as light sources. By analogy to PPVE ${ }^{10}$ PEVE does not absorb significantly at $213.86 \mathrm{~nm}$. Laser fluences of $10-20 \mathrm{~mJ} \mathrm{~cm} \mathrm{~cm}^{-2}$ per pulse resulted in $\mathrm{OH}$ radical concentrations of $(1-2) \times 10^{11}$ molecule $\mathrm{cm}^{-3}$. OH was monitored in real time via its laser-induced fluorescence after exciting the $\mathrm{A}^{2} \Sigma(v=1) \leftarrow \mathrm{X}^{2} \Pi(v=0), \mathrm{Q}_{11}(1)$ transition at $\approx 282 \mathrm{~nm}$ using a frequency-doubled, YAG-pumped Dye-Laser (Quantel Brilliant B plus Lambda-Physik ScanMate II). OH fluorescence was detected using a photomultiplier screened with a $310 \mathrm{~nm}$ interference filter. The photomultiplier signal was accumulated using a box-car integrator (Stanford Research Systems, SR 250).

The other absolute measurements were performed on a similar apparatus (PLP-LIF2) in our laboratory, ${ }^{12}$ which is equipped for both LIF and transient absorption spectroscopy detection schemes. The LIF detection of $\mathrm{OH}$ was similar to that described above, whereas $\mathrm{OH}$ radicals were generated from
$\mathrm{H}_{2} \mathrm{O}_{2}$ in (R2) using the pulsed, $266 \mathrm{~nm}$ emission of a frequency quadrupled Nd:YAG laser (Quantel Brilliant B).

When $\mathrm{H}_{2} \mathrm{O}_{2}$ was used as $\mathrm{OH}$ precursor, the concentration of PEVE was measured in both experimental setups by on-line optical absorption at $184.95 \mathrm{~nm}$ using the cross-section determined in this study. Optically derived concentrations of PEVE agreed to within $\approx 10 \%$ with those calculated from its mixing ratio in the storage bulb and the partial flow and pressure.

Optical measurements of PEVE were not possible when using $\mathrm{HNO}_{3}$ as $\mathrm{OH}$ precursor owing to very large optical extinction due to $\mathrm{HNO}_{3}$ absorption at this wavelength. Instead, PEVE concentrations were calculated from partial flows and the total pressure and cross calibrated against optical measurements in the absence of $\mathrm{HNO}_{3}$.

\subsection{Relative-rate measurements}

The rate coefficient for the reaction of PEVE with $\mathrm{OH}$ radicals was measured in a 441 cylindrical quartz reaction chamber equipped with White-type multi-pass optics providing a $43.7 \mathrm{~m}$ optical path length for infrared absorption spectroscopy. ${ }^{13}$ The reactor was operated at $298 \mathrm{~K}$ and 1 bar total pressure. Six, external, radially mounted, UV photolysis lamps $(30 \mathrm{~W}$, emitting predominantly at $253.65 \mathrm{~nm}$ ) provided a homogeneous light flux within the reactor for radical generation which was initiated by the photolysis of ozone in a large excess of hydrogen:

$$
\begin{gathered}
\mathrm{O}_{3}+h \nu \rightarrow \mathrm{O}\left({ }^{1} \mathrm{D}\right)+\mathrm{O}_{2} \\
\mathrm{O}\left({ }^{1} \mathrm{D}\right)+\mathrm{H}_{2} \rightarrow \mathrm{OH}+\mathrm{H} \\
\mathrm{H}+\mathrm{O}_{2}+\mathrm{M} \rightarrow \mathrm{HO}_{2}+\mathrm{M} \\
\mathrm{H}+\mathrm{O}_{3} \rightarrow \mathrm{OH}+\mathrm{O}_{2} \\
\mathrm{HO}_{2}+\mathrm{O}_{3} \rightarrow \mathrm{OH}+2 \mathrm{O}_{2}
\end{gathered}
$$

$\mathrm{OH}$ precursor concentrations were: $(2.2-10.4) \times 10^{14}$ molecule $\mathrm{cm}^{-3}$ $\mathrm{O}_{3}$ and $(0.1-1.7) \times 10^{17}$ molecule $\mathrm{cm}^{-3} \mathrm{H}_{2}$. Infrared spectra (500-3500 $\mathrm{cm}^{-1}$ ) of PEVE and a reference trace gas were recorded at a resolution of $0.5 \mathrm{~cm}^{-1}$ with a Bruker Vector FTIR instrument with MCT detector.

\subsection{Chemicals}

$\mathrm{N}_{2}$ (Westfalen 99.999\%), $\mathrm{H}_{2}$ (Westfalen 99.999\%), synthetic air (Westfalen), propane (Linde, 99.95\%) and PEVE (Merck, 99\%) were used as supplied without further purification. $\mathrm{H}_{2} \mathrm{O}_{2}$ (Applichem, $50 \mathrm{wt} \%$ ) was concentrated to $>90 \mathrm{wt} \%$ by vacuum distillation. Anhydrous nitric acid was prepared by mixing $\mathrm{KNO}_{3}$ (Sigma Aldrich, 99\%) and $\mathrm{H}_{2} \mathrm{SO}_{4}$ (Roth, 98\%), and condensing $\mathrm{HNO}_{3}$ vapour into a liquid nitrogen trap. To prevent decomposition the nitric acid sample was stored at $-17{ }^{\circ} \mathrm{C}$ between the measurements. $\mathrm{O}_{3}$ was generated by photodissociation of $\mathrm{O}_{2}$, achieved by passing air over a low pressure Hg-lamp emitting at $184.95 \mathrm{~nm}$. 


\section{Results}

\subsection{Absorption cross-section of PEVE at $184.95 \mathrm{~nm}$}

To accurately determine the concentration of PEVE in the PLP-LIF measurements, the cross-section at $184.95 \mathrm{~nm}$ was required. The optical densities (OD) measured at various pressures (1.67-107.0 Torr) of accurately diluted mixtures of PEVE in $\mathrm{N}_{2}$ are shown in Fig. 2. The absorption cross-section, obtained by dividing the slope of a plot of OD vs. [PEVE] by the optical path length, yielded $\sigma_{184.95 \mathrm{~nm}}=(5.61 \pm 0.02) \times 10^{-18} \mathrm{~cm}^{2}$ molecule ${ }^{-1}$ where the errors are $2 \sigma$ statistical only. The total uncertainty is estimated to be $5 \%$ to give a final value of $(5.61 \pm 0.28) \times 10^{-18} \mathrm{~cm}^{2}$ molecule which is very close to that previously measured for perfluoro propyl vinyl ether. ${ }^{10}$ Experiments were conducted using several different sample mixtures to check for systematic errors. The cross-sections obtained were identical within the precision of the measurement.

\subsection{Absolute rate coefficients (207-300 K)}

In the PLP-LIF1 and PLP-LIF2 set-ups, the rate coefficient for the reaction of PEVE with $\mathrm{OH}$ radicals was measured under pseudo-first order conditions with $[\mathrm{PEVE}] \gg[\mathrm{OH}]_{0}$. The $\mathrm{OH}$ radical time profiles are then given by

$$
[\mathrm{OH}]_{t}=[\mathrm{OH}]_{0} \exp \left(-\left[k_{1}[\mathrm{PEVE}]+k_{\mathrm{d}}\right] t\right)
$$

where $k_{1}$ is the bimolecular rate coefficient for the reaction of PEVE with $\mathrm{OH}$ radicals and $k_{\mathrm{d}}$ is the pseudo-first order rate coefficient for other $\mathrm{OH}$ loss processes, mainly reaction with the precursor and diffusion/advection out of the detection zone.

The OH-LIF time profiles were fitted to eqn (i) and example profiles from measurements at $298 \mathrm{~K}$ obtained using PLP-LIF1 are shown in Fig. 3. Each measured OH-LIF time profile is the average of 20-25 measurements and was mono-exponential over at least two orders of magnitude. Rate coefficients for the reaction of $\mathrm{OH}$ with PEVE were obtained by linear fitting of the pseudo-first order rate coefficients as a function of [PEVE], as shown in Fig. 4. The rate coefficients and the experimental

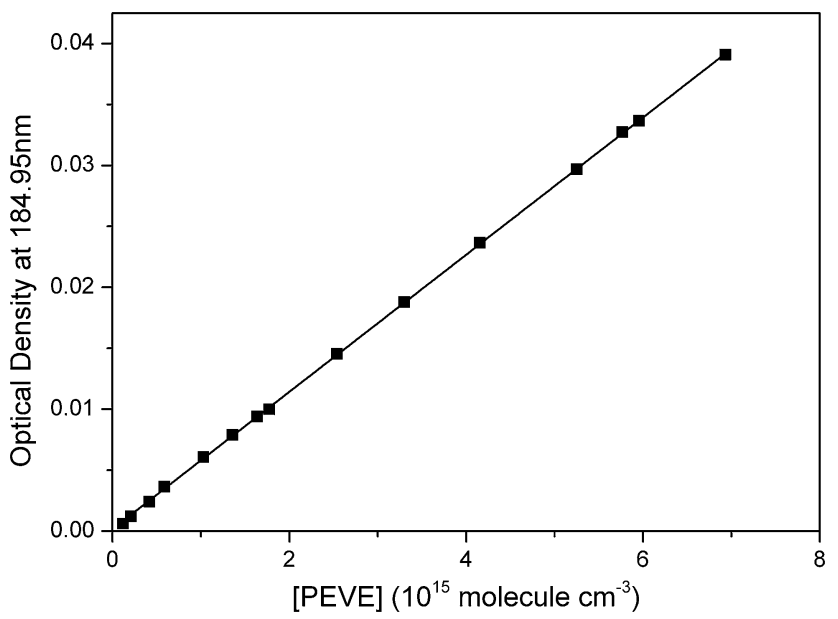

Fig. 2 Beer-Lambert plot of optical density measured at $184.95 \mathrm{~nm}$ versus concentration of PEVE. The effective absorption cross-section of PEVE at $184.95 \mathrm{~nm}$ is $\sigma_{184.95 \mathrm{~nm}}=(5.61 \pm 0.28) \times 10^{-18} \mathrm{~cm}^{2}$ molecule $^{-1}$ including uncertainty from dilution and pressure measurements.

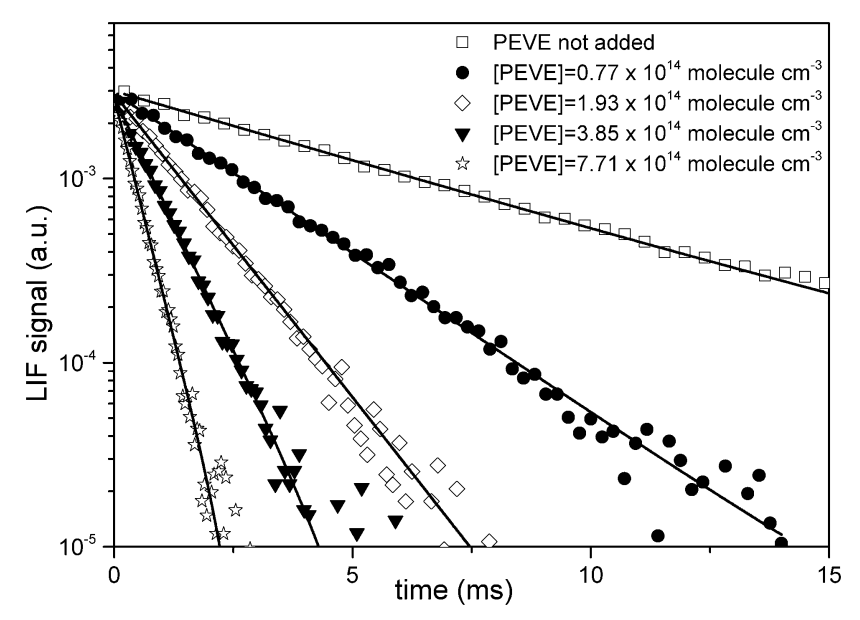

Fig. $3 \mathrm{OH}$ decays in the presence of various concentrations of PEVE at $p=50$ Torr and $T=298 \mathrm{~K} . \mathrm{HNO}_{3}$ photolysis at $248 \mathrm{~nm}$ was used as $\mathrm{OH}$ source.

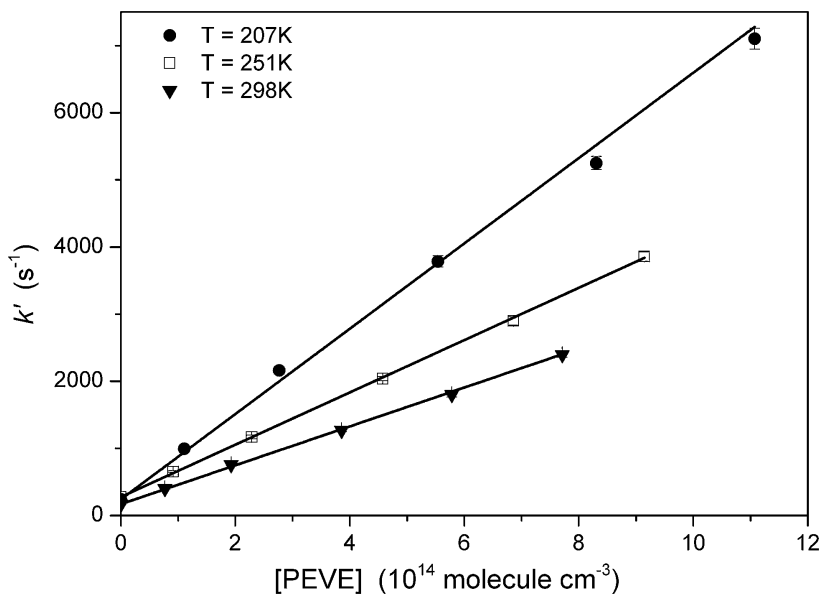

Fig. 4 Plot of pseudo first-order rate coefficient $\left(k^{\prime}\right)$ versus [PEVE] at a total pressure of 50 Torr $\mathrm{N}_{2}$ and at three different temperatures. The data were obtained using the PLP-LIF1 set-up and with photolysis of $\mathrm{HNO}_{3}$ as the $\mathrm{OH}$ precursor. The error bars represent $2 \sigma$ statistical uncertainty and in several cases are smaller than the symbol.

conditions used (temperature, pressure and $\mathrm{OH}$-precursor) are summarised in Table 1.

Values of $k_{1}$ obtained with the two experimental setups and using different $\mathrm{OH}$ precursors show no significant difference and no dependence on pressure between 50 and 100 Torr $\mathrm{N}_{2}$. The rate coefficient does however show a significant, negative temperature dependence.

\subsection{Relative rate coefficients}

In the relative-rate experiments, the loss of PEVE was measured relative to that of propane. Propane was chosen as a reference because it does not react with other compounds in the reaction mixture, does not stick to surfaces and it has a well-established rate coefficient. In the absence of loss processes other than reaction with $\mathrm{OH}$, the depletion factors, $\ln$ (initial concentration/ concentration after time $t$ ), for reactant and reference are 
Table 1 Rate coefficients and experimental conditions for the reaction of $\mathrm{OH}$ with PEVE from PLP-PLIF experiments

\begin{tabular}{lllll}
\hline Setup & $\begin{array}{l}\text { Temp. } \\
(\mathrm{K})\end{array}$ & $\begin{array}{l}\mathrm{OH} \\
\text { precursor }\end{array}$ & $\begin{array}{l}\text { Pressure } \\
\text { (Torr) }\end{array}$ & $\left.\begin{array}{l}k_{1}(T)^{a}\left(10^{-12} \mathrm{~cm}^{3}\right. \\
\text { molecule }\end{array} \mathrm{s}^{-1}\right)$ \\
\hline PLP-LIF1 & 207 & $\mathrm{HNO}_{3}$ & 50 & $6.35 \pm 0.30$ \\
PLP-LIF1 & 225 & $\mathrm{HNO}_{3}$ & 50 & $5.32 \pm 0.31$ \\
PLP-LIF1 & 233 & $\mathrm{HNO}_{3}$ & 50 & $4.59 \pm 0.05$ \\
PLP-LIF1 & 251 & $\mathrm{HNO}_{3}$ & 50 & $3.90 \pm 0.07$ \\
PLP-LIF1 & 260 & $\mathrm{H}_{2} \mathrm{O}_{2}$ & 50 & $3.85 \pm 0.20$ \\
PLP-LIF1 & 268 & $\mathrm{H}_{2} \mathrm{O}_{2}$ & 50 & $3.49 \pm 0.12$ \\
PLP-LIF1 & 270 & $\mathrm{HNO}_{3}$ & 50 & $3.39 \pm 0.08$ \\
PLP-LIF1 & 272 & $\mathrm{H}_{2} \mathrm{O}_{2}$ & 100 & $3.60 \pm 0.12$ \\
PLP-LIF1 & 280 & $\mathrm{H}_{2} \mathrm{O}_{2}$ & 100 & $3.24 \pm 0.09$ \\
PLP-LIF1 & 281 & $\mathrm{H}_{2} \mathrm{O}_{2}$ & 50 & $3.22 \pm 0.12$ \\
PLP-LIF1 & 299 & $\mathrm{HNO}_{3}$ & 50 & $2.90 \pm 0.07$ \\
PLP-LIF1 & 299 & $\mathrm{H}_{2} \mathrm{O}_{2}$ & 50 & $3.04 \pm 0.05$ \\
PLP-LIF1 & 298 & $\mathrm{H}_{2} \mathrm{O}_{2}$ & 100 & $3.03 \pm 0.03$ \\
PLP-LIF2 & 299 & $\mathrm{H}_{2} \mathrm{O}_{2}$ & 50 & $3.02 \pm 0.04$ \\
PLP-LIF2 & 300 & $\mathrm{H}_{2} \mathrm{O}_{2}$ & 50 & $2.95 \pm 0.15$ \\
PLP-LIF2 & 300 & $\mathrm{H}_{2} \mathrm{O}_{2}$ & 50 & $2.96 \pm 0.14$ \\
PLP-LIF2 & 300 & $\mathrm{H}_{2} \mathrm{O}_{2}$ & 50 & $2.70 \pm 0.14$ \\
PLP-LIF2 & 300 & $\mathrm{H}_{2} \mathrm{O}_{2}$ & 100 & $2.75 \pm 0.04$
\end{tabular}

${ }^{a}$ Uncertainty in $k_{1}$ is $2 \sigma$ statistical only.

described by:

$$
\ln \left(\frac{[\mathrm{PEVE}]_{0}}{[\mathrm{PEVE}]_{t}}\right)=\frac{k_{1}}{k_{9}} \ln \left(\frac{[\text { propane }]_{0}}{\left[\text { propane }_{t}\right.}\right)
$$

where $[\mathrm{PEVE}]_{0}$, [propane $]_{0},[\mathrm{PEVE}]_{t}$ and $[\text { propane }]_{t}$ are the concentrations of PEVE and propane at times zero and $t$ respectively, and $k_{1}$ and $k_{9}$ are the rate coefficients of reactions (1) and (9).

$$
\begin{gathered}
\text { PEVE }+\mathrm{OH} \rightarrow \text { products } \\
\mathrm{C}_{3} \mathrm{H}_{8}+\mathrm{OH} \rightarrow \mathrm{C}_{3} \mathrm{H}_{7}+\mathrm{H}_{2} \mathrm{O}
\end{gathered}
$$

The initial concentration ranges used for PEVE and propane were $(1.0-3.3) \times 10^{13}$ molecule $\mathrm{cm}^{-3}$ and $(1.0-4.0) \times 10^{14}$ molecule $\mathrm{cm}^{-3}$, respectively. A typical experiment lasted around one hour, with the photolysis lamps switched on for 5-10 periods of 10-300 s duration for each experiment. The intermittent acquisition of FTIR spectra (64 scans at $0.5 \mathrm{~cm}^{-1}$ resolution) took $\approx 2 \mathrm{~min}$. No significant loss of either PEVE or propane on these time scales was observed in the reaction mixtures including $\mathrm{O}_{3}$ and $\mathrm{H}_{2}$ in the dark.

The time dependent depletion factors for PEVE and propane were obtained by least squares fitting to a reference spectrum in the range $1080-1360 \mathrm{~cm}^{-1}$ for PEVE and $2810-2920 \mathrm{~cm}^{-1}$ for propane. Absorption by products was accounted for by including qualitative reference spectra of the assumed products, $\mathrm{CF}_{2} \mathrm{O},(\mathrm{FCO})_{2}$ and $\mathrm{C}_{2} \mathrm{~F}_{5} \mathrm{OCFO}$ in a spectral fitting procedure using DOASIS software. ${ }^{14}$ An example spectrum with fit and residuals is shown in Fig. 5.

Assuming that the photo-oxidation mechanism for PEVE is similar to those of PMVE and PPVE, perfluoro methoxy radicals $\left(\mathrm{CF}_{3} \mathrm{O}\right)$ are expected to be formed in our experiments. These are known to react with hydrocarbons ${ }^{15}$ and may, in principle, influence our measurements. To assess the potential systematic bias due to reactions of the $\mathrm{CF}_{3} \mathrm{O}$ radical, as well as possible interferences from $\mathrm{O}\left({ }^{1} \mathrm{D}\right)$ reactions with PEVE or propane the concentration of $\mathrm{H}_{2}$, a scavenger of both $\mathrm{CF}_{3} \mathrm{O}$ and $\mathrm{O}\left({ }^{1} \mathrm{D}\right)$, was

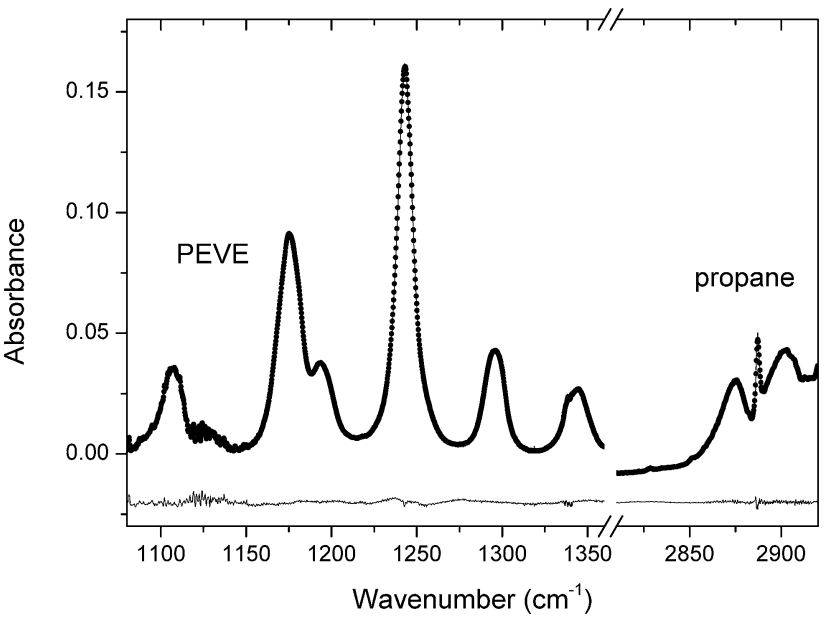

Fig. 5 Spectral range used in the analysis of the relative-rate experiments with recorded spectrum (symbols), fitted reference spectrum (full line) and fit residual (offset by -0.02 absorbance units).

varied by an order of magnitude. As illustrated in Fig. 6 and Table 2, there was no discernible impact on the relative decay rate of PEVE and propane and we conclude that any bias is too small to be significant. In support of this conclusion, numerical simulations ${ }^{16}$ were carried out which used a literature rate coefficient for the reaction of $\mathrm{CF}_{3} \mathrm{O}$ with propane and one for $\mathrm{CF}_{3} \mathrm{O}+\mathrm{H}_{2}$ which was taken to be the same as $\mathrm{OH}+\mathrm{H}_{2}$ $\left(6.7 \times 10^{-15} \mathrm{~cm}^{3}\right.$ molecule ${ }^{-1} \mathrm{~s}^{-1}$ at $\left.298 \mathrm{~K}\right) .{ }^{17}$ The rate coefficient for $\mathrm{CF}_{3} \mathrm{O}+\mathrm{H}_{2}$ is actually likely to be larger as the $\mathrm{CF}_{3} \mathrm{O}$ radical is more reactive than $\mathrm{OH}$ radicals towards hydrocarbons. ${ }^{15}$ The simulations revealed that the reaction of perfluoro methoxy radicals with propane accounts for only $2 \%$ of the total propane loss even at the lowest $\mathrm{H}_{2}$ concentrations, which is in accord with our observations. A total of four relative-rate experiments were performed under different experimental conditions, which are summarised in Table 2 and Fig. 6 . The values of $k_{1} / k_{9}$ from the single experiments agree within $10 \%$ but we may discern a weak,

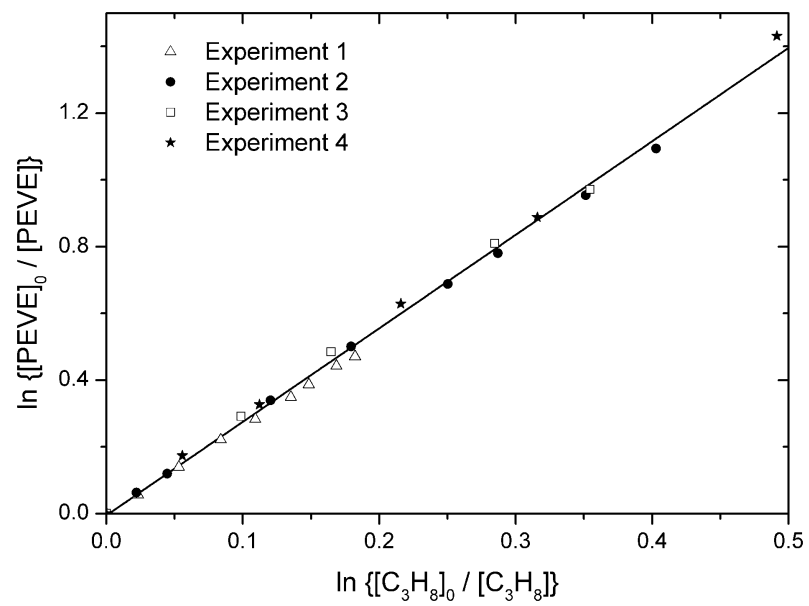

Fig. 6 Fractional loss of PEVE and propane in the presence of $\mathrm{OH}$ radicals from four individual experiments in 750 Torr air diluent. The conditions for each experiment are listed in Table 2. 
Table 2 Summary of experimental conditions in the relative rate study

\begin{tabular}{llllllll}
\hline \multicolumn{5}{l}{ Expt. no. $P$ (Torr) $[\mathrm{PEVE}]_{0}{ }^{a}\left[\mathrm{C}_{3} \mathrm{H}_{8}\right]_{0}{ }^{a}\left[\mathrm{O}_{3}\right]_{0}{ }^{a}\left[\mathrm{H}_{2}\right]_{0}{ }^{b}[\mathrm{OH}]_{0}{ }^{c} k_{1} / k_{9}{ }^{d}$} \\
\hline 1 & 750 & 3.3 & 39.8 & 22.1 & 0.36 & 3.22 & $2.604 \pm 0.032$ \\
2 & 750 & 2.7 & 22.0 & 36.3 & 0.29 & 6.78 & $2.713 \pm 0.030$ \\
3 & 750 & 1.6 & 12.7 & 58.1 & 1.7 & 1.55 & $2.752 \pm 0.108$ \\
4 & 750 & 1.0 & 10.1 & 103.8 & 0.13 & 1.80 & $2.847 \pm 0.042$
\end{tabular}

${ }^{a}$ The initial concentrations of PEVE, $\mathrm{C}_{3} \mathrm{H}_{8}$ and $\mathrm{O}_{3}$ (units of $10^{13}$ molecule $\mathrm{cm}^{-3}$ ) were determined from the IR spectra. ${ }^{b}$ The $\mathrm{H}_{2}$ concentration (units of $10^{17}$ molecule $\mathrm{cm}^{-3}$ ) was derived from pressure measurements. ${ }^{c}$ The $\mathrm{OH}$ concentration (units of $10^{8}$ molecule $\mathrm{cm}^{-3}$ ) from the initial decay of PEVE. ${ }^{d}$ Uncertainty is $2 \sigma$ statistical only.

barely significant positive dependence of the relative rate coefficient on the $\mathrm{O}_{3}$ concentration. i.e. $k_{1} / k_{9}$ changes $($ by $\approx 9 \%$ ) from $2.604 \pm 0.032$ to $2.847 \pm 0.042$ going from the lowest to highest ozone concentration used. Potential explanations for this would be reaction of either $\mathrm{O}_{3}$ or $\mathrm{O}\left({ }^{3} \mathrm{P}\right)$ with PEVE, whereby $\mathrm{O}\left({ }^{3} \mathrm{P}\right)$ is formed in the collisional quenching of $\mathrm{O}\left({ }^{1} \mathrm{D}\right)$ (formed in (R5)) with bath gas. Numerical simulations revealed that the ratio of $\mathrm{O}\left({ }^{3} \mathrm{P}\right) / \mathrm{OH}$ concentrations varied from $\approx 0.01$ to 0.1 between experiments, but this was not accompanied by a significant change in the relative rate constant. We also note that the dark loss of PEVE in the presence of $\mathrm{O}_{3}$ was too small to explain this effect. We have no robust explanation of this weak trend and increase the errors on the rate coefficient obtained by the relative-rate method to take this into account.

A linear least squares fit to all data (solid line in Fig. 6) gives $k_{1} / k_{9}=2.802 \pm 0.061(2 \sigma)$. From this $k_{1}$ can be determined using an evaluated literature value of $k_{9}=(1.1 \pm 0.08) \times$ $10^{-12} \mathrm{~cm}^{3}$ molecule $\mathrm{s}^{-1} \mathrm{~s}^{-118}$ to give $k_{1}=(3.1 \pm 0.35) \times$ $10^{-12} \mathrm{~cm}^{3}$ molecule $\mathrm{s}^{-1} \mathrm{~s}^{-1}$ at $298 \mathrm{~K}$ and 1 bar total pressure of air, where the uncertainty contains both statistical and systematic errors originating from the uncertainty $(7 \%)$ in the literature value for $k_{9}$ and also the potential bias $(<10 \%)$ related to the presence of $\mathrm{O}_{3}$.

\section{Discussion and literature comparison}

The complete dataset, including data obtained using two different experimental setups for determination of the absolute rate coefficient and also the relative rate study is summarised in Fig. 7 as an Arrhenius plot. The room temperature $(298 \pm 2 \mathrm{~K})$ rate coefficients obtained are $k_{1}=(2.97 \pm 0.30) \mathrm{cm}^{3}$ molecule $\mathrm{e}^{-1} \mathrm{~s}^{-1}$ (PLP-LIF1, 50 Torr $\left.\mathrm{N}_{2}\right), k_{1}=(2.90 \pm 0.29) \mathrm{cm}^{3}$ molecule $^{-1} \mathrm{~s}^{-1}$ (PLP-LIF2, 50-100 Torr $\mathrm{N}_{2}$ ) and $k_{1}=(3.1 \pm 0.35) \mathrm{cm}^{3}$ molecule $^{-1} \mathrm{~s}^{-1}$ (relative rate, 750 Torr air). The uncertainties reported for the absolute rate coefficients are dominated by estimated uncertainty in the PEVE cross-section.

The three results are thus in very good agreement, confirming that $k_{1}$ is independent of bath gas identity $\left(\mathrm{N}_{2}\right.$ or air) or pressure between 50 and 750 Torr. Combining all three sets of data at room temperature we derive $k_{1}(298 \mathrm{~K})=(3.0 \pm 0.3) \times$ $10^{-12} \mathrm{~cm}^{3}$ molecule ${ }^{-1} \mathrm{~s}^{-1}$ where the uncertainty is dominated by potential systematic errors in both absolute and relative-rate experiments.

The temperature dependent data obtained using the PLP-LIF1 set-up can be described by an Arrhenius expression: $k_{1}(207-300 \mathrm{~K})=$ $(5.9 \pm 0.8) \times 10^{-13} \exp [(480 \pm 38) / T] \mathrm{cm}^{3}$ molecule ${ }^{-1} \mathrm{~s}^{-1}$, which was derived by instrument-weighted, least-squares fitting to the data displayed in Fig. 7. The negative temperature dependence stems from the formation of an association complex as described for other fluorinated, vinyl ethers. ${ }^{10,23}$

The quoted errors are $2 \sigma$ (statistical only). We adopt the temperature dependence $(480 / T)$ and modify the pre-exponential factor slightly to give the average room temperature rate coefficient from all experiments and obtain: $k_{1}(200-300 \mathrm{~K})=$ $6.0 \times 10^{-13} \exp (480 / T)$ for use in calculation of the rate coefficient at any temperature in the range listed, where the uncertainty will be $10 \%$, independent of temperature.

In the following section, we compare our results with previous literature determinations of rate coefficients for the reactions of $\mathrm{OH}$ with perfluoro methyl vinyl ether (PMVE, $\mathrm{CF}_{3} \mathrm{OCF}=\mathrm{CF}_{2}$ ) and perfluoro propyl vinyl ether (PPVE, $\mathrm{C}_{3} \mathrm{~F}_{7} \mathrm{OCF}=\mathrm{CF}_{2}$ ) which differ from PEVE only in the length of the alkyl chain on the opposite side of the ether linkage to the double bond $\left(\mathrm{CF}_{3}\right.$ versus $\mathrm{C}_{2} \mathrm{~F}_{5}$ versus $\left.\mathrm{C}_{3} \mathrm{~F}_{7}\right)$.

Table 3 lists literature values for room temperature rate coefficients and Arrhenius parameters for the reactions of OH with PMVE, PEVE and PPVE. Note that Mashino et al. ${ }^{8}$ measured the rate coefficient for PMVE with $\mathrm{OH}$ radicals relative to ethene and ethyne at $296 \mathrm{~K}$ in 700 Torr air, and they report a value of $(2.6 \pm 0.3) \times 10^{-12} \mathrm{~cm}^{3}$ molecule ${ }^{-1} \mathrm{~s}^{-1}$. By using their relative rate constants and the most recent IUPAC recommendations ${ }^{18}$ for the ethene $\left(7.8 \times 10^{-12} \mathrm{~cm}^{3}\right.$ molecule $\left.^{-1} \mathrm{~s}^{-1}\right)$ and ethyne $\left(7.5 \times 10^{-12} \mathrm{~cm}^{3}\right.$ molecule $\left.{ }^{-1} \mathrm{~s}^{-1}\right)$ reference reactions we recalculate this to be $(2.2 \pm 0.3) \times 10^{-12} \mathrm{~cm}^{3}$ molecule ${ }^{-1} \mathrm{~s}^{-1}$.

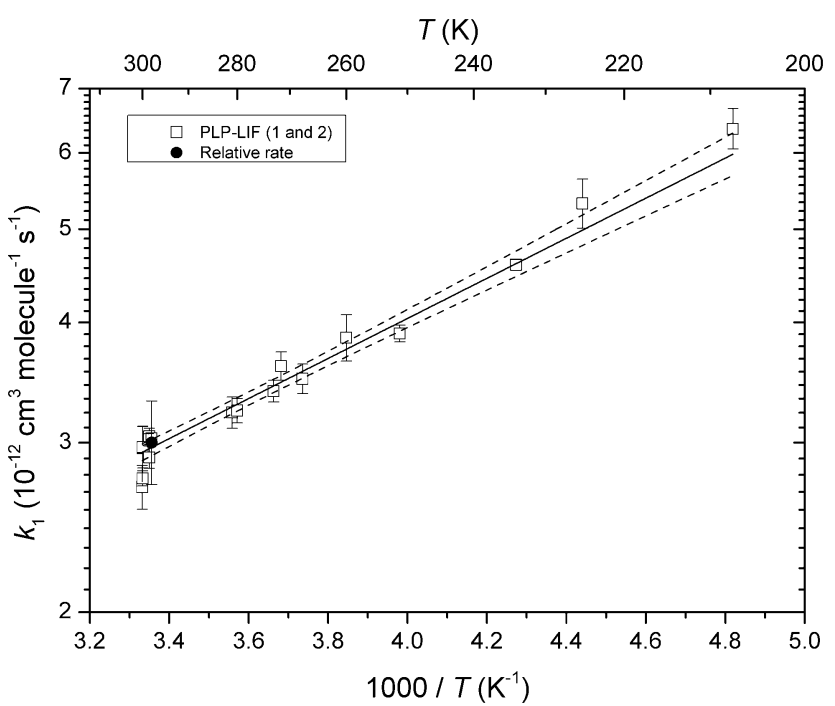

Fig. 7 Arrhenius plot of all data from the present study for the reaction between $\mathrm{OH}$ and PEVE. Open squares: PLP-LIF, filled circle: relative rate. The error bars represent $2 \sigma$ statistical uncertainty. The solid line represents the Arrhenius expression: $k_{1}=5.9 \times 10^{-13} \exp (480 / 7) \mathrm{cm}^{3}$ molecule ${ }^{-1} \mathrm{~s}^{-1}$, the dashed lines are the $95 \%$ confidence intervals. 
Table 3 Rate coefficients and Arrhenius parameters for the reactions of alkyl vinyl ethers with OH radicals

\begin{tabular}{|c|c|c|c|c|}
\hline & $k(298 \mathrm{~K})^{a}$ & $A$ factor $^{b}$ & $E_{\mathrm{a}}{ }^{c}$ & Ref. \\
\hline $\mathrm{CF}_{3} \mathrm{OCF}=\mathrm{CF}_{2}(\mathrm{PMVE})$ & $\begin{aligned} 3.58 & \pm 0.46 \\
2.2 & \pm 0.3^{d}\end{aligned}$ & $641 \pm 82$ & $7.2 \pm 0.3$ & $\begin{array}{l}(\mathrm{Li} \text { et al., 2000) } \\
(\text { Mashino } \text { et al., 2000) }\end{array}$ \\
\hline $\mathrm{CH}_{3} \mathrm{OCH}=\mathrm{CH}_{2}$ & $\begin{array}{l}2.98 \pm 0.3^{e} \\
33.5 \pm 3.4\end{array}$ & $10.1 \pm 0.4$ & $-2.7 \pm 0.1$ & $\begin{array}{l}\text { (Tokuhashi et al., 2000) } \\
(\text { Perry et al., 1977) }\end{array}$ \\
\hline $\begin{array}{l}\mathrm{C}_{2} \mathrm{~F}_{5} \mathrm{OCF}=\mathrm{CF}_{2}(\mathrm{PEVE}) \\
\mathrm{C}_{2} \mathrm{H}_{5} \mathrm{OCH}=\mathrm{CH}_{2}\end{array}$ & $\begin{aligned} 3.0 & \pm 0.3 \\
68 & \pm 7 \\
77.9 & \pm 17.1\end{aligned}$ & $6.0 \pm 0.8$ & $-4.0 \pm 0.3$ & $\begin{array}{l}\text { This work } \\
\text { (Thiault et al., 2002) }^{20} \\
\text { (Zhou et al., 2006) }^{21}\end{array}$ \\
\hline
\end{tabular}

The rate coefficient measured in this work for PEVE is very similar to those reported using absolute techniques by Tokuhashi et al. ${ }^{9}$ for PMVE and by Amedro et al. ${ }^{10}$ for PPVE, both of whom report a room temperature rate coefficient close to 3-4 $\times 10^{-12} \mathrm{~cm}^{3}$ molecule ${ }^{-1} \mathrm{~s}^{-1}$ and a weak, negative temperature dependence. Although the room temperature rate coefficient of Li et $a l^{7}{ }^{7}$ obtained for PMVE is similar to these values, their large activation energy is inconsistent with the other experimental results and also with the fact that the reaction is expected to proceed via electrophilic addition of $\mathrm{OH}$ to the double bond of PMVE. As their experiments were conducted at a pressure of 1 Torr of $\mathrm{He}$, where the high pressure limit is possibly not achieved, a lower room temperature rate coefficient may have been expected rather than a higher one. We have no explanation for this discrepancy, but note that low pressure studies of $\mathrm{OH}$ reactions often suffer from significant $\mathrm{OH}$ wall losses, and pulsed laser systems (essentially wall free) are expected to deliver more accurate results.

Considering only the datasets of Amedro et al. ${ }^{10}$ Mashino et $a l^{8}{ }^{8}$ and Tokuhashi et al. ${ }^{9}$ we can discern a small increase in the rate coefficient with increasing chain length, although this is only just significant given the overall uncertainty reported by each experiment. The change in the negative activation energy is however more obvious, likely reflecting the formation of lower energy transition states on the exit channel to product formation for the larger association complexes formed from addition of $\mathrm{OH}$ to the vinyl ethers, though this has not been predicted by quantum chemical calculations for PMVE and PEVE. ${ }^{10,23}$ Table 3 also lists room temperature rate coefficients for the reaction of non-fluorinated alkyl vinyl ethers. The rate coefficients for the non-fluorinated analogues are significantly larger by factors of 10 to 30 going from methyl-ethyl-propyl substituted alkyl vinyl ethers. As these are largely $\mathrm{OH}$ addition reactions, ${ }^{24,25}$ this significant increase in the rate coefficient reflects the effect of increasing electron density at the double bond through donation from the alkoxy groups. This trend is clearly much weaker (if at all apparent) for the perfluorinated analogues, and may be expected given the more strongly bound electrons in the fluorinated alkyl/alkoxy groups.

The tropospheric lifetime of PEVE can be estimated by assuming uniform, global concentration of $\mathrm{OH}$ radicals. Using a value of
$[\mathrm{OH}] \approx 10^{6}$ molecule $\mathrm{cm}^{-326}$ we estimate a tropospheric lifetime for PEVE due to its reaction with $\mathrm{OH}$ of $\approx 4$ days. This is an order of magnitude shorter that the exchange time for transport to the stratosphere so that, like PPVE, PEVE will be, to a good approximation, completely degraded in the troposphere by reaction with $\mathrm{OH}$. Since its lifetime is short, PEVE is unlikely to have a significant global warming potential. The atmospheric, $\mathrm{OH}$-initiated degradation of PEVE is likely to lead to fluorinated oxygenates such as $\mathrm{CF}_{2} \mathrm{O}$ and $\mathrm{C}_{2} \mathrm{~F}_{5} \mathrm{OCFO},{ }^{10,23}$ though this theoretical result awaits confirmation in experimental product studies, which are presently being undertaken in this laboratory.

\section{Conclusions}

The rate coefficient $\left(k_{1}\right)$ of the reaction of $\mathrm{OH}$ with $\mathrm{C}_{2} \mathrm{~F}_{5} \mathrm{OCF}=\mathrm{CF}_{2}$ (PEVE) has been measured for the first time. Both absolute and relative-rate methods at various pressures and temperatures were applied to derive a value of $6.0 \times$ $10^{-13} \exp (480 / T) \mathrm{cm}^{3}$ molecule $\mathrm{e}^{-1} \mathrm{~s}^{-1}$ with a room temperature value of $(3.0 \pm 0.3) \times 10^{-12} \mathrm{~cm}^{3}$ molecule $\mathrm{s}^{-1} \mathrm{~s}^{-1}$ independent of pressure in the range 50 to 100 Torr $\mathrm{N}_{2}$. The use of three different production schemes for the $\mathrm{OH}$ radical, two different experimental set-ups for the pulsed laser experiments (50 or 100 Torr $\mathrm{N}_{2}$ ) and relative rate constant measurements (750 Torr air) reduce the uncertainty on the rate coefficient to $\approx 10 \%$ at all temperatures. The values of $k_{1}$ obtained are consistent with rate coefficients for reaction of $\mathrm{OH}$ with other fluorinated vinyl ethers and significantly lower than measured for the non-fluorinated analogues. The large $\mathrm{OH}$ rate coefficient ensures that PEVE will not be a persistent fluorinated trace-gas in the atmosphere.

\section{Conflicts of interest}

There are no conflicts to declare.

\section{Acknowledgements}

We thank Merck KGaA for partial financial support of this project and for provision of samples of PEVE. Open Access funding provided by the Max Planck Society. 


\section{Notes and references}

1 A. E. Feiring, in Organofluorine Chemistry: Principles and Commercial Applications, ed. R. E. Banks, B. E. Smart and J. C. Tatlow, Springer, US, Boston, MA, 1994, pp. 339-372, DOI: 10.1007/978-1-4899-1202-2_16.

2 T. Hiyama and H. Yamamoto, in Organofluorine Compounds: Chemistry and Applications, ed. H. Yamamoto, Springer, Berlin, Heidelberg, 2000, pp. 183-233, DOI: 10.1007/978-3662-04164-2_6.

3 S. Ebnesajjad, in Applied Plastics Engineering Handbook, William Andrew Publishing, Oxford, 2011, pp. 49-60, DOI: 10.1016/B978-1-4377-3514-7.10004-2.

4 M. K. W. Ko, N. D. Sze, W. C. Wang, G. Shia, A. Goldman, F. J. Murcray, D. G. Murcray and C. P. Rinsland, J. Geophys. Res.: Atmos., 1993, 98, 10499-10507.

5 M. J. Prather and J. Hsu, Geophys. Res. Lett., 2008, 35, L12810, DOI: $12810.11029 / 12008 g 1034542$.

6 W. T. Sturges, T. J. Wallington, M. D. Hurley, K. P. Shine, K. Sihra, A. Engel, D. E. Oram, S. A. Penkett, R. Mulvaney and C. A. M. Brenninkmeijer, Science, 2000, 289, 611-613.

7 Z. J. Li, Z. N. Tao, V. Naik, D. A. Good, J. C. Hansen, G. R. Jeong, J. S. Francisco, A. K. Jain and D. J. Wuebbles, J. Geophys. Res.: Atmos., 2000, 105, 4019-4029.

8 M. Mashino, M. Kawasaki, T. J. Wallington and M. D. Hurley, J. Phys. Chem. A, 2000, 104, 2925-2930.

9 K. Tokuhashi, A. Takahashi, M. Kaise, S. Kondo, A. Sekiya and E. Fujimoto, Chem. Phys. Lett., 2000, 325, 189-195.

10 D. Amedro, L. Vereecken and J. N. Crowley, Phys. Chem. Chem. Phys., 2015, 17, 18558-18566.

11 M. Wollenhaupt, S. A. Carl, A. Horowitz and J. N. Crowley, J. Phys. Chem., 2000, 104, 2695-2705.

12 C. B. M. Groß, T. J. Dillon, G. Schuster, J. Lelieveld and J. N. Crowley, J. Phys. Chem. A, 2014, 118, 974-985.
13 J. N. Crowley, G. Saueressig, P. Bergamaschi, H. Fischer and G. W. Harris, Chem. Phys. Lett., 1999, 303, 268-274.

14 S. Kraus, DOASIS, DOAS intelligent system, University of Heidelberg, 2006, https://doasis.iup.uni-heidelberg.de/bug tracker/projects/doasis/index.php.

15 S. B. Barone, A. A. Turnipseed and A. R. Ravishankara, J. Phys. Chem., 1994, 98, 4602-4608.

16 A. R. Curtis and W. P. Sweetenham, FACSMILE/CHECKMAT User's Manual, AERE-R12805, Atomic Energy Research Establishment, Harwell, 1988.

17 R. Atkinson, D. L. Baulch, R. A. Cox, J. N. Crowley, R. F. Hampson, R. G. Hynes, M. E. Jenkin, M. J. Rossi and J. Troe, Atmos. Chem. Phys., 2004, 4, 1461-1738.

18 R. Atkinson, D. L. Baulch, R. A. Cox, J. N. Crowley, R. F. Hampson, R. G. Hynes, M. E. Jenkin, M. J. Rossi and J. Troe, Atmos. Chem. Phys., 2006, 6, 3625-4055.

19 R. A. Perry, R. Atkinson and J. N. Pitts Jr., J. Chem. Phys., 1977, 67, 611-614.

20 G. Thiault, R. Thevenet, A. Mellouki and G. Le Bras, Phys. Chem. Chem. Phys., 2002, 4, 613-619.

21 S. Zhou, I. Barnes, T. Zhu, I. Bejan and T. Benter, J. Phys. Chem. A, 2006, 110, 7386-7392.

22 S. A. Peirone, J. P. Aranguren Abrate, R. A. Taccone, P. M. Cometto and S. I. Lane, Atmos. Environ., 2011, 45, 5325-5331.

23 L. Vereecken, J. N. Crowley and D. Amedro, Phys. Chem. Chem. Phys., 2015, 17, 28697-28704.

24 B. Klotz, I. Barnes and T. Imamura, Phys. Chem. Chem. Phys, 2004, 6, 1725-1734.

25 S. Zhou, I. Barnes, T. Zhu, B. Klotz, M. Albu, I. Bejan and T. Benter, Environ. Sci. Technol., 2006, 40, 5415-5421.

26 R. G. Prinn, J. Huang, R. F. Weiss, D. M. Cunnold, P. J. Fraser, P. G. Simmonds, A. McCulloch, C. Harth, P. Salameh, S. O'Doherty, R. H. J. Wang, L. Porter and B. R. Miller, Science, 2001, 292, 1882-1888. 